\title{
Temporality in business networks: The role of narratives and management technologies
}

\author{
Luis Araujo *, Geoff Easton \\ Department of Marketing, Lancaster University Management School, Lancaster LA1 4YX, UK
}

\section{A R T I C L E I N F O}

\section{Article history:}

Received 26 November 2010

Received in revised form 12 December 2011

Accepted 13 December 2011

Available online 26 January 2012

\section{Keywords:}

Process

Tensed and untensed time

Narratives

Management technologies

Business models

\begin{abstract}
A B S T R A C T
This paper addresses the nature of temporality in business networks. Approaches to temporality generally employ a dualistic approach: time can be understood as social and natural, tensed and untensed, subjective and objective, kairos or chronos, agency and structure. We examine these two approaches and suggest that the problem for situated actors is how to cope with and negotiate with these dualities. This is particularly salient in cases of innovation, when actors attempt to bring about their particular versions of the future facing acute problems of uncertainty. The innovation literature highlights the role of narrative in helping actors to negotiate uncertainty and construct spaces for action in a world of continuous flow. The emphasis on narrative tends to obscure the role of management technologies in anchoring narratives into existing routines and procedures as well as relate these technologies to the untensed world of chronos. Management technologies help stabilise entities and relationship amongst entities in what otherwise is a chaotic world of events and flux.
\end{abstract}

(c) 2012 Elsevier Inc. All rights reserved.

\section{Introduction}

The issue of process and temporality has been explored in the business network literature from a variety of angles both theoretical (see e.g. Easton \& Araujo, 1999; Araujo \& Harrison, 2002; Medlin, 2004; Mattsson \& Andersson, 2006, 2009; Hedaa \& Törnroos, 2008) and methodological (see e.g. Halinen \& Tornroos, 1995; Dubois \& Araujo, 2004). The focus has largely been on explaining change and evolution in business networks, modelling sequences of events (e.g. as path-dependent trajectories) and deriving methodological principles to study change.

In this paper, we want to take up the perspective of the situated actor to understand temporality and process. Our purpose is to examine alternative conceptions of temporality and to attempt to build a picture of change that starts with the present, the here and now, confronting an uncertain future. Our argument is that situated actors combine different notions of temporality to make sense of history and their choices through credible narratives that link past, present and future.

The paper is structured as follows. In the next section we examine different approaches to temporality and process focusing on the dualities that underpin many conceptions of time. In the third section, we use innovation processes as a case to examine the role of narrative in making sense of ontological uncertainty. In the fourth section, we examine how a variety of management technologies help actors

\footnotetext{
* Corresponding author. Tel.: + 441524 510989x510990; fax: +44 1524510935 E-mail addresses: l.araujo@lancaster.ac.uk (L. Araujo), g.easton@lancaster.ac.uk (G. Easton).
}

cope with the uncertainties of the future before offering some concluding comments in the final section. Our main argument is that narratives and management technologies embody alternative notions of temporality that are mixed and matched in creative ways during innovation processes.

\section{Temporality and process in the social sciences}

The vast majority of writings on time appear to converge on the notion that time can be conceptualised as having a dualistic nature. Gidden's structuration theory, for example, offers a highly influential dualist model. Giddens (1984: 374) argues that structure is “...the medium and the outcome of the conduct it recursively organises: the structural properties of social systems do not exist outside of action but are chronically implicated in its production and reproduction". Structuration theory involves the notion of reversible and irreversible time (Giddens, 1984: 35). Some processes are irreversible in terms of their outcomes (e.g. the life span of an individual). Others are taken to be reversible since they involve processes such as the events and routines of daily life that have a recursive rather than a one-way flow associated with them.

Archer (1995), in distinguishing between structure and agency, argues that these two categories interact in ways which we need to understand if we are to make causal statements about events in the world. In particular she suggests that there are two kinds of processes involving structure and agency. Morphogenesis refers to processes that lead to change or elaboration of social systems. Morphostasis refers to those processes that preserve the existing system. Understanding 
events requires a causal model of how these two processes reciprocally influence one another.

Another example of a dualistic approach to time, contrasting natural and social approaches, is provided by Abbott (2005: 408). He resurrects the distinction originally made by J. M. E. McTaggart in 1908, between two approaches to temporality: the A and B time series. The A series involves a continuous flow between past, present and future. Time is conceived in terms of tense. The B series involves another scale for thinking about time - time is simply a transitive order relation, events are rank ordered in terms of "earlier" or "later than". Time is thus reduced to chronological dates.

Abbott uses the contrast between the two series to develop a broader argument: the A series emphasises a continuous flow of events, whilst the B series parses time into discrete chunks emphasising mere duration. Similarly, the ancient Greeks recognised two types of time symbolised by two gods, Kairos and Chronos. Kairos identified time as flow, a sequence of qualitatively heterogeneous events. Chronos, on the other hand, represented the metrological notion of time, the division of time into common units and the establishment of common standards to measure time (Hedaa and Törnroos, 2002). Czarniawska (2004a: 775) remarks: "Whereas Chronos measures time in mechanical intervals, Kairos jumps and slows down, omits long periods and dwells on others".

Gell (1992) makes a similar distinction between the A and B series. For Gell, the B series time is objective, untensed time. Notions of past, present and future, are fleeting attributes of events that are constantly being remade as time flows. As Hodges (2008) remarks, Gell regards the B series as a statement about the objective, autonomous nature of real time. Events exist, have clear relationships to each other and provide bedrock to connect the world to its history. Nevertheless, human beings also experience events and change by anchoring their perceptions in A-series time, the subjective, tensed existence involving past, present and future. For Gell (1992: 240):

"Our access to time is confined to the A series flux through which we interact with 'real' time, via the mediation of temporal maps which provide us with a surrogate for real time. These constructions of B-time series are not the real thing... but we are obliged to rely on them".

In summary, the A series approach is typically regarded as the province of subjective human experience, whilst the B series approach is associated with metrological approaches to time and the rise of space-time stretching brought about by late modernity (Giddens, 1987). The history of time metrology and the emergence of standard time, arising out of the need to align and coordinate multiple local times, are told by Zerubavel (1982), Landes (1983), Joerges (2003), and Glennie and Thrift (2009) amongst others. The link between time reckoning systems and the rise of industrial capitalism were explored in a seminal piece by Thompson (1967) and the role of time systems in organisational life and industrial systems has been examined by numerous authors (see e.g. the essays in Whipp, Adams, \& Stabelis, 2002).

Abbott (2005) observes that the social sciences incorporate different views of temporality. Neoclassical economics is taken to be a prime example of a B series enterprise. Critics, such as Shackle (1966: 18), have a dimmer view of how neoclassical economics addresses time:

"Equilibrium is rationality and is the sole means of perfect rationality. Now what are the implications of this construction for those involved? It implies a momentary society, a cosmos of action which effectively exists only for one moment, a timeless system."

An example of a B series approach in economics is represented by the discount utility model for modelling intertemporal choice. The model assumes that the value of a sequence of outcomes is equal to the discounted sum of utilities in each period. The distribution of utility across time is irrelevant beyond what is dictated by the discount rate. A positive time preference assumes that people value immediate utility and far-sighted behaviour can be explained by positing utility derived from the anticipation of future consumption (Fredrick, Loewenstein, \& O'Donoghue, 2002).

Investment decisions, for example, can be appraised by looking forward to potential results weighted by the probability of their occurrence, and comparing outcomes folded back into the present (the net present value of future cashflows) where decisions are made. One can look forward to future rewards but these are weighed down by past investments - sunk costs. Uncertainties between now and that specified future may intervene to reduce the value of future rewards, hence the preference towards something that can be enjoyed immediately. In short, the future can be forecasted but is somewhat uncertain, whilst the past is known but irrelevant for current decisions. Other schools of thought, critical of the neoclassical approach, take a different approach to the subjects of time, uncertainty and ignorance (see e.g. Shackle, 1958; Parsons, 1991; Setterfield, 1995; O'Driscoll \& Rizzo, 1996; Loasby, 1999, 2001).

The approach taken by classical contracting is similarly based on the notion of presentiation, or anticipating all future contingencies and folding them into the present. For Macneil (1974: 589): "Presentiation is thus a recognition that the course of the future is bound by present events, and that by those events the future has for many purposes been brought effectively into the present". In classic contracting, as Macneil (1980) memorably put it, the goal of parties to a transaction is to bring everything from the past and future into the immediate present thereby creating a compressed and bounded time-frame sharp-in, sharp-out.

Abbott (2005) points out that many social sciences have a strong B series orientation. They assume social processes take place along a time line and select a specific period, which may vary considerably in length, to study in detail. Beginnings and ends of these time frames are largely arbitrary but once labelled as processes leading to a specified outcome (e.g. a change programme), they are rendered comparable. It is within these time frames that we can study processes focusing on the evolution of one particular entity (e.g. a firm, a network).

Van de Ven and Poole (1995: 512), for example, describe process as the progression in terms of order and sequence, of events in an organisational entity's existence over a specified time period. Change is seen as one type of event, registering a difference in form, quality or state of the entity over the time period. That entity may be anything from a localised initiative (e.g. implementing a TQM programme in a manufacturing plant), to a material entity (e.g. a new product) or something that affects a whole organisation (e.g. a corporate strategy) or even a whole organisational field (e.g. implementing technical standards). In all these cases, we face the problem of specifying beginning and ends of a sequence and developing an explanation as to how and why the entity of interest changed within that time period. Once we abstract and formalise processes of change, regardless of the time frames or the focal entities involved, we can indulge the quest for generalisation and construct ideal-theoretical processes of change (Van de Ven \& Poole, 1995).

\section{Temporality and situated action}

The above discussion raises two issues which we will attempt to address in the remainder of this paper:

1) What is the relationship between tensed and untensed outcomes, between the A and B time series approach to temporality?

2) How should we address temporality from the point of view of the situated actor rather than the detached, disembedded analyst?

To address the first question is to reopen the discussion that Gell (1992) attempted to settle with the notion that we rely on the B- 
series whilst we live in the A-series world. It is easy to concur with Abbott's (2005) statement, that we live in a social and institutional environment that is fundamentally tensed. The notion of agency proposed by Emirbayer and Mische (1998), for example, highlights this tensed existence. Agency is seen as a temporally embedded process, not only informed by the past (privileging habits and routines) but also oriented toward the future (as a "projective" capacity to imagine future scenarios). The present, often seen as the agential moment, is regarded as a "practical-evaluative" capacity to contextualize past habits and future projects within the contingencies of the "here and now".

This view of agency is heavily influenced by George Herbert Mead's view that the present is the paramount form of temporality (Flaherty \& Fine, 2001). It is in the present that we can observe and act as opposed to recalling or anticipating events. Mead proposed that the constant flux of events and their interpretation means that the past is open to reconstruction as it is constantly being reinterpreted in light of novel experiences. As Flaherty and Fine (2001: 153) put it: "From this perspective, the past is a resource, not a cage. Instead of being imprisoned in it, we use it to make sense of the present and imagine the future".

As Abbott (2005) notes, we want our concepts to work in a tensed environment that can encompass the meaningful experience of situated actors. Moves to untensed outcomes may become necessary if we need to compare outcomes across agents or across different time periods, but this is regarded as fundamentally undesirable (Abbott, 2005: 419). This preference for the use of a tensed temporality calls for a perspective that embraces process and interaction, in contrast to approaches that emphasise the primacy of entities and their changes within prescribed time frames.

This worldview is described as relational and contrasted with substantialist modes of thinking (Emirbayer, 1997). Substantialist modes of thinking take as a starting point the notion that entities of various kinds (e.g. firms) constitute the fundamental unit of enquiry and that systematic analysis should start with these preformed entities before considering the interactions in which they involve themselves. One common type of substantialist thinking reduces all explanations to individuals or collections of individuals. Neoclassical economics, for example, starts with rational, calculative actors and assumes the fixity of their interests, preferences and traits as they interact with similar actors. Another type of substantialist thinking focuses on the analysis of wholes and regards self-subsistent entities such as "structures" or "socio-economic systems" as sources of action (Bunge, 2000; Emirbayer, 1997).

Abbott (1995) argues that theories that presume given fixed entities always fall apart over the problem of explaining change. The problem is usually handled by falling back on the static, given character of those entities. Relational approaches reject both the individualist and holistic variants of substantialist thinking and regard entities involved in interactions as deriving their meaning, significance and identity from the role they play within those interactions. It is interactions, seen as dynamic and unfolding processes that become the unit of analysis rather than the entities themselves (Emirbayer, 1997).

Abbott (1995) argues that if we begin with interaction as the focal point of enquiry, the units of analysis might be anything (e.g. a firm). But rather than seeing interaction as an opportunity for entities to reproduce themselves, no entity can hope to cross interactions unscathed. The trick to explain change is to begin with it and hope to explain stasis as a by-product of change. An entity is thus a continuous swirl of interlinked practices that struggles to acquire a degree of coherence and autonomy, in order to establish boundaries that mark it off from other entities. In this sense, social actors are not fixed entities but rather "events with stable lineages", something to be explained rather than assumed (Abbott, 1995: 863). In his study of the development of the Chicago school of sociology, Abbott (1999) depicts a fluid and changeable entity rather than a coherent school of thought undergoing changes over time. As he puts it: "The continuity of names should not fool us into believing in the continuity of the named" (ibid: 223).

Abbott's approach highlights the need to pay attention to unfolding, emergent character of action and how social entities are constantly inthe-making rather than fully stabilised. Action should thus be seen as situated in time and understood in terms of the circumstances that frames it. The notion of situated action was first proposed by Suchman (1987) and contrasted with rational, abstract plans as guides to action. As she explained: "That term [situated action] underscores the view that every course of action depends in essential ways upon its material and social circumstances. Rather than attempting to abstract action from its circumstances and represent it as a rational plan, the approach is to study how people use their circumstances to achieve intelligent action" (ibid: 50). To study situated action is thus to pay close attention to the material and social circumstances of action, to examine how actors make sense of their actions as they happen, to give a prominent place to a temporally-sensitive view of agency. Moreover, a situated action perspective sees agency as a capacity built through distributed associations including material devices, which are always likely to evolve and shift according to specific circumstances. This view can be contrasted with approaches that regard individuals as the only possible form of agency (see Callon, 2008).

In the remainder of this paper, we will attempt to show how understanding action in the face of uncertainty requires an examination of how the A and B time series, kairos and chronos, are invoked and used by situated actors to make sense of their actions in the here and now. Czarniawska (2004a) makes a strong case for studying the interplay between kairotic and chronological time in organising. One argument suggested by Czarniawska (2004a: 776) is that chronology organises the present and the immediate future whilst kairotic time governs the past and distant future. Both forms of time are involved in organising; kairotic time allows for a degree of temporal autonomy, deciding on priorities, deferrals and so on. But, as Czarniawska (2004a: 777) argues, if organisations ran purely on kairotic time nothing would ever run on time, no deadline would ever be respected. Plans, budgets, calendars, clocks, project schedules and so on, ensure that chronological time plays a key role in organising.

In the remainder of the paper we will focus on the role of narratives and management technologies in helping situated actors cope with the uncertainties involved in innovation processes. Narratives are commonly associated with kairotic time and management technologies with chronological time. Organising in general, and innovation in particular, depend critically on both kairotic narratives and dispersed calculations (Czarniawska, 2004a).

\section{The role of narratives in innovation}

The context of our subsequent discussion is innovation since it provides a particularly apt setting to examine how kairotic and chronological times interact. Innovation processes are highly situated and contingent (Hoholm, 2011; Pavitt, 2005; Van de Ven, Polley, Garud, \& Venkataraman, 1999). They involve a subtle balance between path dependence and creation (Garud \& Karnøe, 2001, 2003). In path dependence, temporally remote events shape possibilities for the emergence of novelty, whilst path creation focuses on the role of situated actors as they attempt to shape history in the making. Innovators stand at the intersection of past, present and future. They offer interpretations of past history, actively shape objects and contexts of action, mobilise resources based on a particular version of the future which they attempt to render "real".

Lane and Maxfield (2005: 8) distinguish between three types of uncertainty: truth uncertainty, semantic uncertainty and ontological uncertainty. In truth uncertainty, actors are uncertain as to whether a particular propositional statement is true or not. Thus we may be able to make a number of propositional statements about the future 
and measure their truth uncertainty in relation to a probability scale. Investment decisions, for example, can be modelled according to a sequential tree of events and contingencies with associated probabilities for each, with net present values attached to each branch.

In semantic uncertainty, actors are uncertain about the meaning of propositions. Innovations generate new artefacts and new functionalities which may be open to a variety of interpretations in relation to existing frames. Ontological uncertainty poses different challenges. In ontological uncertainty, actors are simply unable to generate stable propositions about what kinds of entities inhabit the world, how they interact with each other and what types of effects these entities and interactions generate into the future.

For Lane and Maxfield (2005), the way actors hold ontological uncertainty at bay is through narrative embedding. The meaning of the word "narrative" is not devoid of ambiguity - see Czarniawska (2004b) for a fuller discussion of narratives in social science research. Ricoeur (1980) sees narrativity and temporality as reciprocally related and the narrative structure that is most relevant to explore the temporal implications of narrativity is the "plot". By plot, Ricoeur (1980: 171) means the intelligible whole that gives meaning to the succession of events in a story. Thus a story is made out of events to the extent that a plot turns a succession of events into a story. For Ricoeur, the plot articulates the link between narrativity and temporality. An event acquires meaning through its contribution to the development of a plot. Through plots events are drawn together and the situated actors in these plots are seen as purposefully engaged with the flow of events and as having a bearing on the outcomes. Similar approaches to narrative are offered by Polkinghorne (1988) and Griffin (1993) amongst others.

In strategy research, the notion of narrative has been deployed to understand how situated actors construct coherent stories about the evolution of the firm and the direction of change (see Araujo \& Easton, 1996; Barry \& Elmes, 1997; Dunford \& Jones, 2000; Fenton \& Langley, 2011). In times of uncertainty and change, “...stories about directionality are variously appropriated, discounted, championed and defended" (Barry \& Elmes, 1997: 432). In short, narratives are crucial vehicles for understanding how futures are deemed desirable and possible, and how different versions of the future are fought over and negotiated.

For Lane and Maxfield (2005: 12), narratives can only work within particular communities, groups of people who already share particular narrative structures or genres. A narrative structure consists of a set of character types, plot elements and a series of typical outcomes. The strength of narrative structures, as Lane and Maxfield (2005) suggest, lies in their subtle combination of teleology and indeterminacy. The teleological element within a recognised narrative structure, leads the audience towards a recognised destination whilst indeterminacy resides in the twists and turns of a route that is not mapped in advance.

How do narrative structures help actors navigate through ontological uncertainty? According to Lane and Maxfield (2005: 15), a narrative logic provides an immanent link between the characters and the unravelling of a plot. Whilst a narrative is in place, a narrator can carry on enacting it, even if narrative structures contemplate all manners of obstacles and diversions. By framing otherwise discrete and disparate events into a narrative structure, actors are able to confront ontological uncertainty by temporarily stabilising entities and their relationships whilst leaving room to accommodate changes.

Deuten and Rip (2000) studied a product creation process through the lens of what they called a "narrative infrastructure". In a product creation process, there are multiple and multilayered stories that evolve in unexpected ways. Sometimes a master narrative emerges out of these dispersed efforts by mutual adjustments amongst heterogeneous stories. Some building blocks get adopted, recycled and developed to become accepted ingredients in other stories thus generating a narrative infrastructure. As Deuten and Rip (2000: 74) put it: "When a narrative infrastructure evolves out of the stories, actions and interactions of the actors involved, actors become characters that cannot easily change their identity and role by their own initiative".

Stories have thus a multi-faceted and ambiguous character. In start-up stories, the product-to-be and its insertion into a context occupy centre stage which allows for a project team to emerge and mobilise resources and support. Once formed, the project team continues to construct narratives about the product-to-be, its role inside the company and its impact in the wider world. It is the product that will stand as triumphant at the end of this narrative whilst traces of its creation will become invisible or get assimilated into a linearised and compact version of the story (Hoholm, 2011). By contrast, in stories about innovation failure, the failed innovation fades from view and the role of those involved in the failure comes into the foreground.

Bartel and Garud (2009) distinguish between structured and provisional narratives to highlight the difference between structured plots and a story that attempts to slot fragments of activity into an emerging plot. Structured and provisional narratives interact over time, as structured narratives give rise to new courses of action and provisional narratives consolidate into more orderly stories. Narratives are seen as playing a key role in resolving the coordination problems in innovation. They enable the translation of ideas across specialist functions, reduce ambiguity and equivocal meanings, and enable the translation of past history into relevant and current meanings to inform the innovation effort. In this sense, stories suggest both causal links in a sequence of events as well as allow people to talk about potential things-to-be, linking them to existing contexts.

Similarly, Simakova and Neyland (2008) highlight the role of narratives in constructing a market for a new product. The articulation of market relations through internal and external stories about a new technology is closely aligned with the creation of a market constituency. These stories must be made compelling, i.e. they must succeed in bringing the members of the envisaged constituency to enact the articulated relations. The task of management is to keep together mutually consistent definitions of constituencies and stories. But these stories do not necessarily remain stable for any one constituency or coherent across constituencies, much as Deuten and Rip (2000) suggest. There is a constant danger that they lose their compelling character, as they fail to hold the attention of, and capacity to, mobilise constituencies.

The role of narratives as a means of coping with semantic and ontological uncertainty is thus well-rehearsed in the innovation literature. Narratives craft coherence amongst otherwise disparate and fragmented events, allow for coordination and communication across specialist boundaries and help mobilise support for particular courses of action. As Deuten and Rip (2000) point out, multiple stories can come into an alignment to form a narrative infrastructure without the intervention of any master narrator. The existence of a narrative infrastructure does not invalidate the notion that multiple stories may still be told to a variety of audiences or that ambiguity disappears. The strength of narratives lies in their subtle combination of teleology and indeterminacy, their ability to make sense of events whilst preserving the possibility of revising interpretations.

However, the attention to narrative and its role in making sense of a tensed existence tend to neglect the role of managerial technologies in building up coherent and credible narratives. Our contention is that there is a reciprocal relation between narratives and management technologies. Management technologies help build up credible narratives whilst they produce outcomes that can be only be interpreted within particular narrative structures.

\section{Management technologies and innovation}

Cooper (1992: 257) observes that administrators or managers do not work directly on the environment, but on models, maps, numbers and formulae that represent that environment. Events that are remote in space and time can be represented in a variety of formats 
(e.g. paper, computer screens) through chains of measurement and translation. As Cooper notes, remote control is a form of displacement that turns the representation into a substitution for an event and never the event itself. We use the term management technologies to describe the multiple forms of representations that abbreviate, condense and represent the main features of economic environments and render these domains governable (Miller \& Rose, 1990).

As Czarniawska and Mouritsen (2009: 172) explain, management technologies simplify complex objects such as people, technologies and organizations, by representing these objects as sets of simplified traits and making them visible as discrete entities. It is this separation of objects from their network relations that allows control and intervention. But this simplification is not without costs. Management technologies move some things into the foreground whilst obscuring others and the representations they produce are never definitive. Alternative representations are always possible, producing new framings and new overflows (Callon, 1998).

The technologies of accounting and its metrological infrastructures have received particular attention (see e.g. Hopwood \& Miller, 1994; Power, 2004). But technologies of managing are used in many other domains such as operations (e.g. lean supply), strategy (e.g. business plans) or marketing (e.g. category management).

Mouritsen and Dechow (2001) make a cogent argument about the role of management technologies in making particular realities visible and durable. Managerial technologies help objectify and reproduce historical experience. Narratives and stories about the future do not start from tabula rasa nor can they make themselves credible without anchoring themselves in recognised procedures. To put it differently, narrative structures in organisations are constrained and enabled by a host of management technologies. To create stories that resonate with the right audiences requires an acknowledgment of what counts as credible arguments and what entities and associations need to be mobilised to create compelling narratives. Rather than seeing narratives as inhabiting the A time series and management technologies as anchored in the B series, we need to study their interaction in practice.

Mouritsen and Dechow (2001) argue that narratives only gain pragmatic content when inscribed in appropriate procedures fitted to existing managerial technologies. Managerial technologies guide the exploration of future alternatives without just reproducing existing procedures or exploiting past experience. Narratives carve out semantic spaces of exploration of the future but this exploration can be guided in different ways, depending on which managerial technologies are mobilised to support that exploration. For example, the notion of redefining supplier relationships according to a template of "world class supply" by a purchasing department cannot simply rely on the rhetorical force of a generic argument for "world class supply" (Mouritsen \& Dechow, 2001: 370). Credible narratives rely on the mobilisation of existing notions such as profit, investment, control, and organisational knowledge, to build a network of associations supporting the move towards "world class" supply relations. Choosing to place emphasis on say, cost reductions or the technological competence of suppliers, leads to the mobilisation of different management technologies as well as suggesting where the competencies required to manage supplier relations are to be found.

In summary, management technologies are the means to translate stories into narratives that have pragmatic content. Narratives about the future open up new semantic spaces that are confronted with the existing infrastructures of management technologies and established routines. These semantic spaces do not acquire a performative character on their own; they require the means to turn visions about the future into reality. Management technologies provide the means to enact such translations. In this sense, management technologies are a source for mobilising history although their employment is not restricted by how they have been used in the past. To paraphrase Mouritsen and Dechow (2001), management technologies mobilise history to make history.
Mouritsen, Hansen, and Hansen (2009) make another useful argument on the role of management technologies in innovation processes. Management technologies have the power to mobilise others, to represent the detailed and varied practices involved in innovation as well as contextualise innovation within a broader set of concerns. As Mouritsen et al. (2009) show, this process is mediated by short and long translation chains relating the innovation to varying contexts and concerns. In shorter translations, innovation activities are contextualised with a direct link to a particular calculative frame (e.g. variance from a standard budget). In longer translations, the types of calculation may be long and variegated, taking into account activities inside and outside the firm (e.g. sourcing strategies, interorganisational relationships). The longer the chain of associations mobilised to contextualise an innovation, the more probable we will find trade-offs, accommodations and tensions that problematise both the content and the context of the innovation (e.g. what role should suppliers play in the innovation?).

Doganova and Eyquem-Renault (2009) provide another example of how management technologies and narratives work together in innovation contexts. Their focus is on the role of business models to steer innovations such as a new venture based on a novel technology into existence. The notion of a business model is usually understood as a mediator between technology and economic value (Chesbrough \& Rosenbloom, 2002; Doganova, 2010; Mason \& Leek, 2008). Business models articulate value propositions, identify customers and markets, define the structure of activities required to deliver value to customers, estimate the cost and revenue drivers of constructing offerings, and position the business in a value network outlining its relationships to suppliers, customers and significant third parties (e.g. complementary suppliers). These attributes are often used in presentations to investors, to request financial capital, as well as sketching possible trajectories of evolution of the business.

A business model incorporates both a story-telling dimension (does it provide a compelling narrative?) and a calculative dimension (do the numbers add up and sound plausible?). As business models circulate amongst different types of communities, different narrative structures are used for different audiences. Calculation and storytelling go hand in hand. A world is created and populated by entities (e.g. customers, suppliers) that interact within the narrative structure created by the business model. These entities are also calculated in the sense that they are associated with metrics and numbers (e.g. costs, revenues). These associations help stabilise the entities and their role within the narrative, thus lending credibility to the business model as a device that can help mobilise support and resources. Narratives and calculation work in tandem when a business model is deployed. By lending more weight to the narrative or calculative dimension, the presentation of a business model can be adapted to the requirements of different audiences without disturbing its overall integrity.

Doganova and Eyquem-Renault (2009) see the temporality of the business model as residing firmly in kairos, the stereotypical entrepreneur's ability to seize the right moment to act. But business models, precisely because of their subtle mix of narrative and calculation, have a foot in both kairos and chronos. As Doganova and Eyquem-Renault (2009) suggest, the business model is but a modest scale model of a new venture, a vehicle for demonstrating the feasibility of a possible future and enrolling the support of others. In its encounters with potential partners and supporters, it systematically engages with chronos, an organised world of metrological infrastructures that attempt to relate narratives to a multiplicity of calculative devices. If the business model resists these trials of strengths and succeeds in enrolling allies, it begins to perform the world it narrates with every successful iteration. As Doganova and Eyquem-Renault (2009: 1568) put it: "This process gradually transforms the business model from a model into a business".

Miller and O'Leary (2007) examine how what they call "mediating instruments", defined as the practices that frame the capital spending 
decisions of firms and agencies, embody particular versions of the future. They examine the case of the US semiconductor industry and how instruments such as Moore's law and technological roadmaps link up science and the economy. Moore's law, which predicts that the number of transistors that can be placed in an integrated circuit doubles approximately every two years, and associated technological roadmaps serve to both tell the industry forward - to paraphrase Deuten and Rip (2000) - and coordinate a series of investment decisions across a multitude of firms and organisations, such as the National Semiconductor Association. Thus the mediating instruments that Miller and O'Leary (2007) invoke play a role in bringing together different domains (science and the economy), coordinate a series of parallel and complementary investments as well as contributing to bring about the predictions embodied by Moore's law.

\section{Conclusions}

Our main argument in this paper is that the dualistic notions of temporality, variously expressed as the A versus B time series, tensed versus untensed lifeworlds, kairos versus chronos, or subjective versus objective time, have consequences for how we understand action in business networks. In this paper, we have taken a situated action perspective in contrast with earlier approaches that have sought to understand change in from a more macro and detached perspective. A situated action perspective emphasises the social and material circumstances of action and regards agency as distributed. It pays attention to how actors simultaneously deal with interpretations of the past, are actively involved in shaping objects and contexts of action, and attempt to bring about their own versions of the future.

We have used an innovation context to examine the interplay between kairos and chronos. Gell's (1992) notion that we lived in a tensed world that coexists with an untensed but "real" world, establishes a clear but ultimately unsatisfactory division of labour. The tensed world is the world of subjective experience, of events with varying qualities, where temporal and causal successions often get blurred. The untensed world is constructed by the metrological infrastructures that turn time into an objective, universal entity, with accompanying time reckoning devices (e.g. calendars, timetables) that allow for the coordination of social action across space and time.

The tensed world is a world of flow and relations, a world that is best understood through narrative. The untensed world, by contrast, is a world of management technologies, metrological infrastructures and calculation, following Czarniawska and Mouritsen (2009). Management technologies simplify a complex world, by abstracting and creating entities that stand for the phenomena they represent.

Our suggestion is that as situated actors approach uncertain futures, as in innovation processes, they make use and combine tensed and untensed approaches to temporality. The examples we have quoted demonstrate that when faced with ontological uncertainty, situated actors are faced with the task of (temporarily) stabilising entities and their relations to make sense of the possibilities of action in the "here and now". This process of stabilisation requires the construction of compelling narratives, combining teleology and indeterminacy. Teleology allows for the insertion of events into plots that can be recognised as examples of particular narrative genres, whilst indeterminacy allows for plots to be continuously revised in light of the novel and unpredictable. However, plots are not just stories in the narrow sense of providing a plausible ordering for a sequence of events. In order to enrol others, to mobilise support and resources for a cause, narratives make use of a range of management technologies to construct credible interpretations of the past and create compelling versions of the future.

The approach suggested in this paper has two major implications for studying business networks. First, on the basis of a situated action approach, we need a better grasp of the varied tensions between chronological and kairotic time in the way actors structure and make sense of their actions. This calls for a heightened sensitivity to the way action is structured by management technologies, from traditional accounting and control systems to the multitude of coordination devices embedded in modern information systems. Although there is an emerging stream of contributions in this area (see e.g. Håkansson et al., 2010), much remains to be done to address this topic. Second, we need to hone our theoretical and methodological approaches to capture the messiness, uncertainty and situatedness of action in business networks. This implies taking a closer look at events in-the-making, getting closer to the challenges that situated actors face as they happen. Our suggestion is that ethnography, despite its many challenges in organisational and interorganisational settings, provides a viable methodological strategy to address situated action in business networks (Hoholm, 2011; Hoholm \& Araujo, 2011). This does not invalidate the need for more distant and macro approaches to understanding change in business networks. But it does highlight the need for theoretical and methodological strategies that place temporality, stability and change as key concepts to study business networks.

\section{References}

Abbott, A. (1995). Things of boundaries. Social Research, 62(4), 857-882.

Abbott, A. (1999). Department and discipline: Chicago sociology at one hundred. Chicago: University of Chicago Press.

Abbott, A. (2005). Process and temporality in sociology. The idea of outcome in US sociology. In G. Steinmetz (Ed.), The politics of method in the human sciences (pp. 393-426). Durham, NC: Duke University Press.

Araujo, L., \& Easton, G. (1996). Strategy - Where is the pattern ? Organization, 3(3), 361-383.

Araujo, L., \& Harrison, D. (2002). Path dependence, agency and technological evolution. Technology Analysis \& Strategic Management, 14(1), 5-19.

Archer, M. (1995). Realist social theory: A morphogenetic approach. Cambridge: Cambridge University Press.

Barry, D., \& Elmes, M. (1997). Strategy retold: Toward a narrative view of strategic discourse. Academy of Management Review, 22(2), 429-452.

Bartel, C. A., \& Garud, R. (2009). The role of narratives in sustaining organizational innovation. Organization Science, 20(1), 107-117.

Bunge, M. (2000). Ten modes of individualism - None of which works - And their alternatives. Philosophy of the Social Sciences, 30(3), 384-406.

Callon, M. (1998). An essay on framing and overflowing: Economic externalities revisited by sociology. In M. Callon (Ed.), The laws of the market (pp. 244-269). Oxford: Basil Blackwell.

Callon, M. (2008). Economic markets and the rise of interactive agencements: From prosthetic agencies to habilitated agencies. In T. Pinch, \& R. Swedberg (Eds.), Living in a Material World. Economic Sociology Meets Science and Technology Studies (pp. 29-56). Cambridge, MA: The MIT Press.

Chesbrough, H., \& Rosenbloom, R. S. (2002). The role of the business model in capturing value from innovation: evidence from Xerox Corporation's technology spin-off companies. Industrial and Corporate Change, 11(3), 529-555.

Cooper, R. (1992). Formal organisation as representation: Remote control, displacement and abbreviation. In M. Reed, \& M. Hughes (Eds.), Rethinking organisation: New directions in organisation theory and analysis (pp. 254-272). London: Sage.

Czarniawska, B. (2004). On time, space, and action nets. Organization, 11(6), 773-791.

Czarniawska, B. (2004). Narratives in social science research. London: Sage.

Czarniawska, B., \& Mouritsen, J. (2009). What is the object of management? In C. S. Chapman, D. J. Cooper, \& P. Miller (Eds.), Accounting, organizations, and institutions: essays in honour of Anthony Hopwood (pp. 157-174). Oxford: Oxford University Press.

Deuten, J. A., \& Rip, A. (2000). Narrative infrastructure in product creation processes. Organization, 7(1), 69-93.

Doganova, L. (2010). Faire valoir l'exploration collective. Dynamiques, instruments et résultats des partenariats avec des spin-off académiques. PhD thesis, Centre de Sociologie de l'Innovation. Paris, École Nationale Supérieure des Mines de Paris.

Doganova, L., \& Eyquem-Renault, M. (2009). What do business models do? Innovation devices in technology entrepreneurship. Research Policy, 38(10), 1559-1570.

Dubois, A., \& Araujo, L. (2004). Research methods in industrial marketing studies. In H. Håkansson, D. Harrison, \& A. Waluszewski (Eds.), Rethinking marketing. Developing a new understanding of markets (pp. 207-228). Chichester: John Wiley.

Dunford, R., \& Jones, D. (2000). Narrative in strategic change. Human Relations, 53(9), 1207-1226.

Easton, G., \& Araujo, L. (1999). Discontinuities in networks: Issues and initiatives as initiators. In P. Ghauri (Ed.), International marketing and purchasing, 9. (pp. 91-108) Greenwich, CT: JAI Press.

Emirbayer, M. (1997). Manifesto for a relational sociology. The American Journal of Sociology, 103(2), 281-317.

Emirbayer, M., \& Mische, A. (1998). What is agency? The American Journal of Sociology, 103(4), 962-1023.

Fenton, C., \& Langley, A. (2011). Strategy as practice and the narrative turn. Organization Studies, 32(9), 1171-1196. 
Flaherty, M., \& Fine, G. A. (2001). Present, past, and future: Conjugating George Herbert Mead's perspective on time. Time \& Society, 10(2-3), 147-161.

Fredrick, S., Loewenstein, G., \& O'Donoghue, T. (2002). Time discounting and time preference: A critical review. Journal of Economic Literature, 40(2), 351-401.

Garud, R., \& Karnøe, P. (2001). Path creation as a process of mindful deviation. In R. Garud, \& P. Karnøe (Eds.), Path dependence and creation (pp. 1-38). Mahwah, NJ: Lawrence Erlbaum Associates Inc..

Garud, R., \& Karnøe, P. (2003). Bricolage versus breakthrough: distributed and embedded agency in technology entrepreneurship. Research Policy, 32(2), 277-300.

Gell, A. (1992). The anthropology of time. Oxford: Berg.

Giddens, A. (1984). The constitution of society. Cambridge: Polity Press.

Giddens, A. (1987). Time and social organisation. In A. Giddens (Ed.), Social theory and modern sociology (pp. 140-165). Cambridge: Polity Press.

Glennie, P., \& Thrift, N. (2009). Shaping the Day. A History of Timekeeping in England and Wales 1300-1800. Oxford: Oxford University Press.

Griffin, L. J. (1993). Narrative, event-structure analysis, and causal interpretation in historical sociology. The American Journal of Sociology, 98(5), 1094-1133.

Håkansson, H., Kraus, K., \& Lind, J. (Eds.). (2010). Accounting in networks. Routledge series in accounting. London: Routledge.

Halinen, A., \& Tornroos, J. -A. (1995). The meaning of time in the study of industrial buyer-supplier relationships. In K. Moller, \& D. T. Wilson (Eds.), Business marketing: An interaction and network perspective (pp. 493-529). Norwell, Mass.: Kluwer.

Hedaa, L., \& Törnroos, J. -A. (2002). Towards a Theory of Timing: Kairology in Business Networks. In R. Whipp, B. Adams and I. Stabelis (Eds), Making Time. Time and Management in Modern Organizations (pp. 31-45). Oxford, Oxford University Press.

Hedaa, L., \& Törnroos, J. -A. (2008). Understanding event-based business networks. Time E Society, 17(2-3), 319-348.

Hodges, M. (2008). Rethinking time's arrow: Bergson, Deleuze and the anthropology of time. Anthropological Theory, 8(4), 399-429.

Hoholm, T. (2011). The contrary forces of innovation: An ethnography of innovation in the food industry. London: Palgrave Macmillan.

Hoholm, T., \& Araujo, L. (2011). Studying innovation processes in real-time: The promises and challenges of ethnography. Industrial Marketing Management, 40(6), 933-939.

Hopwood, A. G., \& Miller, P. (Eds.). (1994). Accounting as a social and institutional practice. Cambridge: Cambridge University Press.

Joerges, B. (2003). Reflections on the millennium. In B. Joerges, \& H. Nowotny (Eds.), Social studies of science and technology: Looking back, ahead (pp. 261-292). Dordrecht: Kluwer.

Landes, D. S. (1983). Revolution in time: Clocks and the making of the modern world. Cambridge, MA: Belknap Press.

Lane, D. A., \& Maxfield, R. R. (2005). Ontological uncertainty and innovation. Journal of Evolutionary Economics, 15(1), 3-50.

Loasby, B. J. (1999). Knowledge, institutions and evolution in economics. London: Routledge.

Loasby, B. J. (2001). Time, knowledge and evolutionary dynamics: Why connections matter. Journal of Evolutionary Economics, 11(4), 393-412.

Macneil, I. R. (1974). Restatement (Second) of contracts and presentiation. Virginia Law Review, 60(4), 589-610.

Macneil, I. R. (1980). The new social contract: An inquiry into modern contractual relations. New Haven, CT: Yale University Press.

Mason, K. J., \& Leek, S. (2008). Learning to build a supply network: An exploration of dynamic business models. Journal of Management Studies, 45(4), 774-799.

Mattsson, L. -G., \& Andersson, P. (2006). Construction of temporal profiles and the shaping of markets. Paper presented at the 22nd IMP Conference, Bocconi University, Milan.

Mattsson, L. -G., \& Andersson, P. (2009). Temporal orientation and temporal profiles of network adjustments in times of economic recession. Paper presented at the 25th IMP Conference, Euromed, Marseille.

Medlin, C. J. (2004). Interaction in business relationships: A time perspective. Industrial Marketing Management, 33(3), 185-193.
Miller, P., \& O'Leary, T. (2007). Mediating instruments and making markets: Capital budgeting, science and the economy. Accounting, Organizations and Society, 32(7-8), 701-734.

Miller, P., \& Rose, N. (1990). Governing economic life. Economy and Society, 19(1), 1-31.

Mouritsen, J., \& Dechow, N. (2001). Technologies of managing and the mobilization of paths. In R. Garud, \& P. Karnøe (Eds.), Path dependence and creation (pp. 355-379). Mahwah, NJ: Lawrence Erlbaum Associates Inc.

Mouritsen, J., Hansen, A., \& Hansen, C. O. (2009). Short and long translations: Management accounting calculations and innovation management. Accounting, Organizations and Society, 34(6-7), 738-754.

O'Driscoll, G. P., \& Rizzo, M. J. (1996). The economics of time and ignorance. New York: Routledge.

Parsons, S. D. (1991). Time, expectations and subjectivism: Prolegomena to a dynamic economics. Cambridge Journal of Economics, 15(4), 405-423.

Pavitt, K. (2005). Innovation process. In J. Fagerberg, D. C. Mowery, \& R. R. Nelson (Eds.) The Oxford handbook of innovation (pp. 86-114). Oxford: Oxford University Press.

Polkinghorne, D. (1988). Narrative knowing and the human sciences. Albany, NY: State of New York University Press.

Power, M. (2004). Counting, control and calculation: Reflections on measuring and management. Human Relations, 57(6), 765-783.

Ricoeur, P. (1980). Narrative time. Critical Inquiry, 7(1), 169-190.

Setterfield, M. (1995). Historical time and economic theory. Review of Political Economy, $7(1), 1-27$.

Shackle, G. L. S. (1958). Time in economics. (Amsterdam, North Holland).

Shackle, G. L. S. (1966). The nature of economic thought. Selected papers 1955-1964. Cambridge: Cambridge University Press.

Simakova, E., \& Neyland, D. (2008). Marketing mobile futures: Assembling constituencies and creating compelling stories for an emerging technology. Marketing Theory, 8(1) 91-116.

Suchman, L. (1987). Plans and situated actions: The problem of human-machine communication. New York: Cambridge University Press.

Thompson, E. P. (1967). Work, time-discipline and industrial capitalism. Past and Present, 38, 56-97.

Van de Ven, A., Polley, D. E., Garud, R., \& Venkataraman, S. (1999). The innovation journey. New York: Oxford University Press.

Van de Ven, A. H., \& Poole, M. S. (1995). Explaining development and change in organizations. Academy of Management Review, 20(3), 510-540.

Whipp, R., Adams, B., \& Stabelis, I. (Eds.). (2002). Making time. Time and management in modern organizations. Oxford: Oxford University Press.

Zerubavel, E. (1982). The standardisation of time: A socio-historical perspective. The American Journal of Sociology, 88(1), 1-29.

Luis Araujo is Professor of Industrial Marketing at Lancaster University Management School. His research is broadly related to how and why industrial firms form different types of exchange relationships, and engage in particular types of market practices. Recent publications include Reconnecting Marketing to Markets (Oxford University Press) co-edited with John Finch and Hans Kjellberg.

Geoff Easton is Emeritus Professor in the Department of Marketing at Lancaster University Management School. His main research interests are B2B markets and marketing, organisational and managerial behaviour, strategic practices, critical realism and case teaching methods. He has published in Industrial Marketing Management, Journal of Management Studies, OMEGA, British Journal of Management, European Journal of Marketing, Organization, Journal of Business Research, Journal of World Business and Complex Systems Advances. 